\title{
OCENA BODŹCÓW RUCHOWYCH ODPOWIEDZIALNYCH ZA WYSTECPWANIE CHOROBY SYMULATOROWEJ
}

\author{
RAFAE LEWKOWICZ \\ Wojskowy Instytut Medycyny Lotniczej, Warszawa \\ e-mail: rlewkowicz@wiml.waw.pl
}

\begin{abstract}
Przedstawiona praca jest próbą określenia przyczyny występowania w dynamicznym symulatorze lotu nieprzyjemnych doznań ruchowych niespotykanych w locie rzeczywistym. Celem przeprowadzonych badań była odpowiedź na pytanie, czy szybkość zmiany przyspieszenia liniowego kabiny wirówki przeciążeniowej może mieć związek z występowaniem u pilota objawów choroby lokomocyjnej. W badaniu zastosowano bodziec ruchowy w postaci profilu przyspieszeń interwałowych utworzonych przy wykorzystaniu modelu kinematyki wirówki przeciążeniowej HTC-07. Każdy z pięciu utworzonych profili różnił się szybkościa zmiany generowanego przyspieszenia $(1,2,3,4$ lub $6 \mathrm{G} / \mathrm{s})$. Do oceny bodźców odpowiedzialnych za występowanie choroby symulatorowej zastosowano model nasilenia objawów choroby lokomocyjnej oparty na teorii subiektywnego poczucia kierunku grawitacji. Badania przeprowadzone metodą symulacji komputerowej wykazały, że w każdym z analizowanych profili występuje bodziec ruchowy odpowiedzialny za występowanie choroby lokomocyjnej. Stwierdzono występowanie nieliniowej zależności między nasileniem objawów tej choroby a szybkością zmiany przyspieszenia kabiny wirówki. Najniższy poziom nasilenia objawów wystąpił dla zmian przyspieszenia z przedziału od 2 do $4 \mathrm{G} / \mathrm{s}$.
\end{abstract}

Stowa kluczowe: symulator lotu, wirówka przeciążeniowa, choroba symulatorowa, model choroby lokomocyjnej

\section{Wstęp}

Wykorzystanie symulatorów w badaniach, szkoleniach i treningach łączy się często z występowaniem niekorzystnego zjawiska określanego jako choroba symulatorowa [1], [2]. O chorobie tej mówimy wówczas, gdy jej objawy są rezultatem wyłącznie ekspozycji w symulatorze, a nie są obecne $\mathrm{w}$ warunkach rzeczywistych odtwarzanych $\mathrm{w}$ tym urządzeniu. Zjawisko to jest wciąż nie do końca poznane i dotyczy prawie każdego uczestnika symulacji [2], [3].

Choroba symulatorowa wpływa negatywnie na rzetelność pomiaru, efektywność treningu, jak również może przyczyniać się do przerwania wykonywanego w symulatorze zadania [4], [5]. Charakteryzuje się ona różnymi objawami, w dużym stopniu podobnymi do objawów choroby lokomocyjnej, począwszy od złego samopoczucia, senności, poprzez pocenie się, bóle i zawroty głowy do zaburzeń równowagi, a także zaburzeń żołądkowo-jelitowych (mdłości i wymioty). Niektóre objawy mogą ustąpić dopiero po upływie kilkunastu godzin po opuszczeniu symulatora i moga w tym czasie stanowić potencjalne zagrożenie bezpiecznego wykonywania zadań [3]. Stało się to podstawą do sformułowania m.in. czasowych ograniczeń w wykonywaniu lotów w warunkach rzeczywistych [6]. Jeżeli w wyniku treningu pilot wykazywał objawy choroby symulatorowej, to loty takie mogą odbywać się dopiero po 12 godzinach po całkowitym ustąpieniu tych objawów.

Podatność na chorobę symulatorową zależna jest od wieku, cech osobniczych i może wzrastać w wyniku zmęczenia, przeziębienia, a także silnego stresu [2], [7]. Na wystąpienie choroby symulatorowej wpływa również wiele innych czynników [8], wśród których, podobnie jak w przypadku 
choroby lokomocyjnej, wymienia się niezgodność pomiędzy sygnałami odbieranymi z narządów wzroku, przedsionkowego i mechanoreceptorów (receptory czucia płytkiego i głębokiego). Wywoływana $\mathrm{w}$ ten sposób choroba symulatorowa, z uwagi na podobny mechanizm powstawania oraz zakres objawów, będzie w prezentowanym badaniu traktowana tożsamo z chorobą lokomocyjną.

Duże indywidualne różnice w podatności na chorobę symulatorową oraz jej wieloobjawowość powodują, że dotychczas nie opracowano skutecznego narzędzia do obiektywnego pomiaru poziomu nasilenia tej choroby. Stosowane są zatem metody pomiaru polegającej na samoocenie [9], w której uczestnik wskazuje rodzaj i nasilenie rozpoznanych u siebie objawów. Z uwagi na subiektywny charakter badania te coraz częściej wspierane są obliczeniami numerycznymi, na potrzebę których wykorzystuje się modele nasilenia objawów choroby lokomocyjnej [10]. Najbardziej popularnym i najczęściej stosowanym w badaniach i modelowaniu choroby lokomocyjnej jest podejście polegające na poszukiwaniu interakcji pomiędzy ruchem i objawami tej choroby. W podejściu tym stosowane są obecnie dwie teorie: konfliktu sensorycznego (ang. Sensory Conflict theory, SC) [11]-[14] oraz konfliktu subiektywnego poczucia kierunku grawitacji (ang. Subjective Vertical Conflict theory, SVC) [15].

\subsection{Choroba symulatorowa $\mathrm{w}$ wirówce przeciążeniowej}

Szkolenie i trening pilotów we współczesnych wirówkach przeciążeniowych, pełniących funkcję symulatora lotu, związane są niejednokrotnie z nieprzyjemnymi doznaniami ruchowymi, które nie są spotykane w locie rzeczywistym. Do jednego z tych niekorzystnych bodźców ruchowych zalicza się procedurę zmiany generowanego w symulatorze przyspieszenia liniowego. W celu zmiany wytwarzanego przeciążenia zmianie ulegają prędkość kątowa ramienia oraz kąt przechylenia kabiny symulatora (rys. 1). Z uwagi, że proces ten trwa stosunkowo krótko (od jednej do kilku sekund), to metoda oceny objawów choroby lokomocyjnej oparta na pomiarze wybranych parametrów fizjologicznych bądź kwestionariuszu samooceny może wykazać niską skuteczność. W takiej sytuacji wyniki badań numerycznych mogą udzielić odpowiedzi na pytanie, które z wytwarzanych przez symulator bodźców ruchowych w największym stopniu mogą prowokować wystąpienie objawów choroby lokomocyjnej. Wiedza ta może być przydatna w opracowaniu nowych metod sterowania ruchem kabiny tego symulatora, umożliwiających wyeliminowanie lub przynajmniej zmniejszenia nieprzyjemnych doznań ruchowych. Przedstawiona praca jest próbą określenia przyczyny występowania tych doznań ruchowych i zaproponowania metody zmniejszania ich niekorzystnego wpływu.

\subsection{Cel badań}

Celem przeprowadzonych badań była odpowiedź na pytanie, czy szybkość zmiany przyspieszenia liniowego kabiny wirówki przeciążeniowej może mieć związek z występowaniem u pilota objawów choroby lokomocyjnej. Wyniki dotychczasowych badań [16] wskazują, że przyspieszenia liniowe o wysokich i stałych wartościach nie wpływają na wystąpienie objawów choroby lokomocyjnej, podczas gdy cykliczna zmiana tego przyspieszenia może sprzyjać wystąpieniu objawów chorobowych. Na tej podstawie postawiono hipotezę, że nasilenie objawów choroby lokomocyjnej zależy od szybkości zmian przyspieszenia liniowego.

\section{Metoda badania}

\subsection{Schemat badania}

Badanie bodźców ruchowym odpowiedzialnych za występowanie choroby symulatorowej przeprowadzono metodą symulacji komputerowej. Bodźcami ruchowymi były profile przyspieszeń interwałowych, wygenerowane przy wykorzystaniu modelu kinematyki wirówki przeciążeniowej 
HTC-07. Do oceny tych bodźców zastosowano model nasilenia objawów choroby lokomocyjnej (model MSI). W celu wskazania bodźców, które w najwyższym stopniu mogą przyczyniać się do wywoływania objawów tej choroby, porównano wartości MSI oszacowane przez model niezależnie dla każdego profilu przyspieszeń.

\subsection{Obiekt badań}

W badaniu wykorzystano bodźce ruchowe wytwarzane w wirówce przeciążeniowej HTC-07 (AMST-Systemtechnik GmbH, Austria), znajdującej się w Wojskowym Instytucie Medycyny Lotniczej. Symulator ten ma układ ruchu o 3 stopniach swobody (rys. 1), który z kabiną zawieszoną na 8-metrowym ramieniu, umożliwia generowanie przyspieszeń liniowych jednocześnie względem trzech osi. Zakres wytwarzanego przyspieszenia oraz parametry kinematyki układu ruchu symulatora HTC-07 zamieszczono w pracach [17], [18].

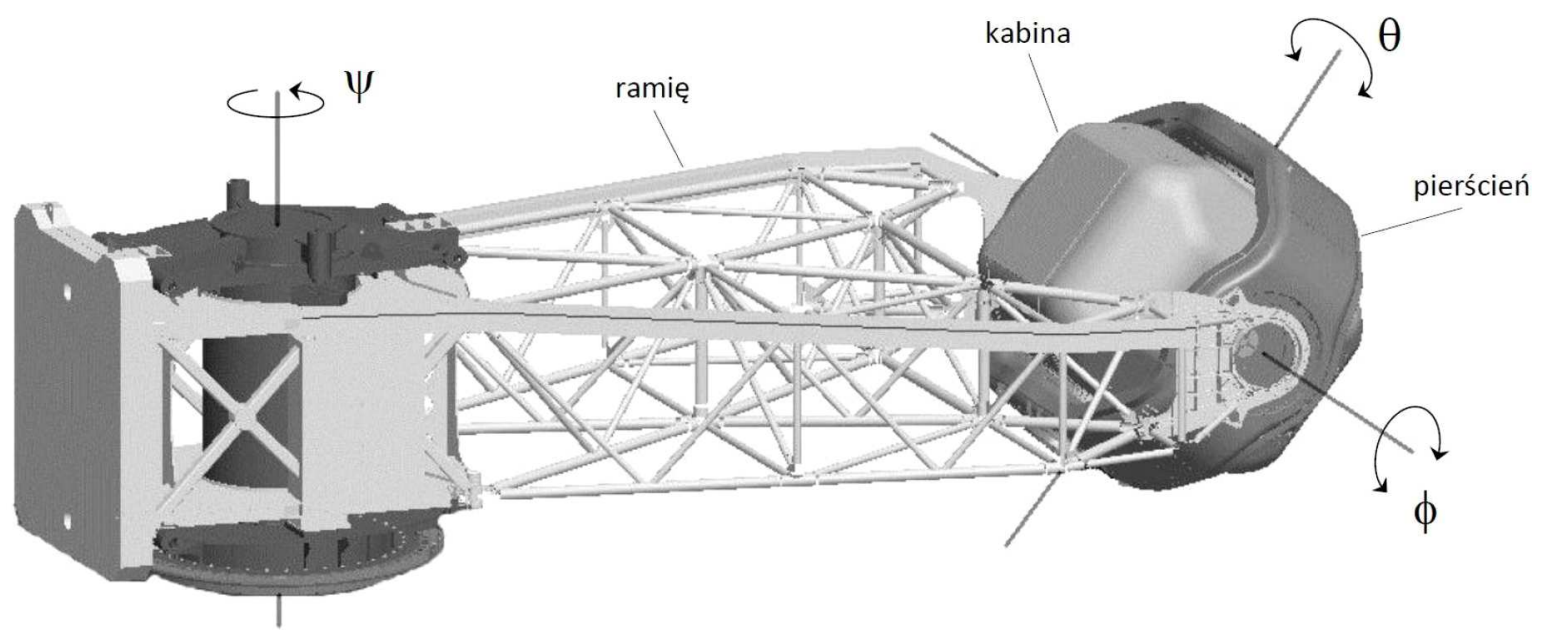

Rys. 1. Kąty opisujące przestrzenna konfigurację kabiny symulatora HTC-07 [17]

\subsection{Profile bodźców ruchowych}

W celu określenia związku między szybkością zmiany przyspieszenia a poziomem nasilenia objawów choroby lokomocyjnej zastosowano pięć profili bodźców ruchowych w postaci przyspieszeń interwałowych z maksymalną wartością przyspieszenia $+6 \mathrm{G}_{\mathrm{z}}$, różniących się prędkością zmiany tego przyspieszenia $(1,2,3,4 \mathrm{lub} 6 \mathrm{G} / \mathrm{s})$. Prędkość zmiany przyspieszenia była taka sama zarówno dla procedury narastania, jak i spadku przyspieszania. Poziom $+1,4 \mathrm{G}_{\mathrm{z}}$ linii bazowej przeciążenia wyjściowego przyjęto zgodnie z wartością ustaloną dla wirówki przeciążeniowej HTC-07. Czas trwania każdego z czterech stałych przyspieszeń na poziomie $+6 \mathrm{G}_{\mathrm{z}}$ wynosił $15 \mathrm{~s}$. Przyspieszenia te wygenerowano w odstępach 15-sekundowych, zachowując jednakowy 160sekundowy czas trwania każdego profilu. Według Burtona i współpracowników [19] wartość i czas trwania zastosowanego w badaniu przyspieszenia określane jest jako wysokie i długotrwałe przyspieszenie, które reprezentuje obciążenie doświadczane przez pilota podczas rzeczywistej walki powietrznej.

Zastosowane $\mathrm{w}$ badaniu profile przyspieszeń utworzono przy wykorzystaniu modelu kinematyki wirówki przeciążeniowej HTC-07, który opisano szerzej w pracach [20], [21]. Na rys. 2 przedstawiono przykładowe parametry kinematyki układu ruchu symulatora HTC-07, które obliczono dla przyspieszeń zmieniających się z szybkością $3 \mathrm{G} / \mathrm{s}$. 

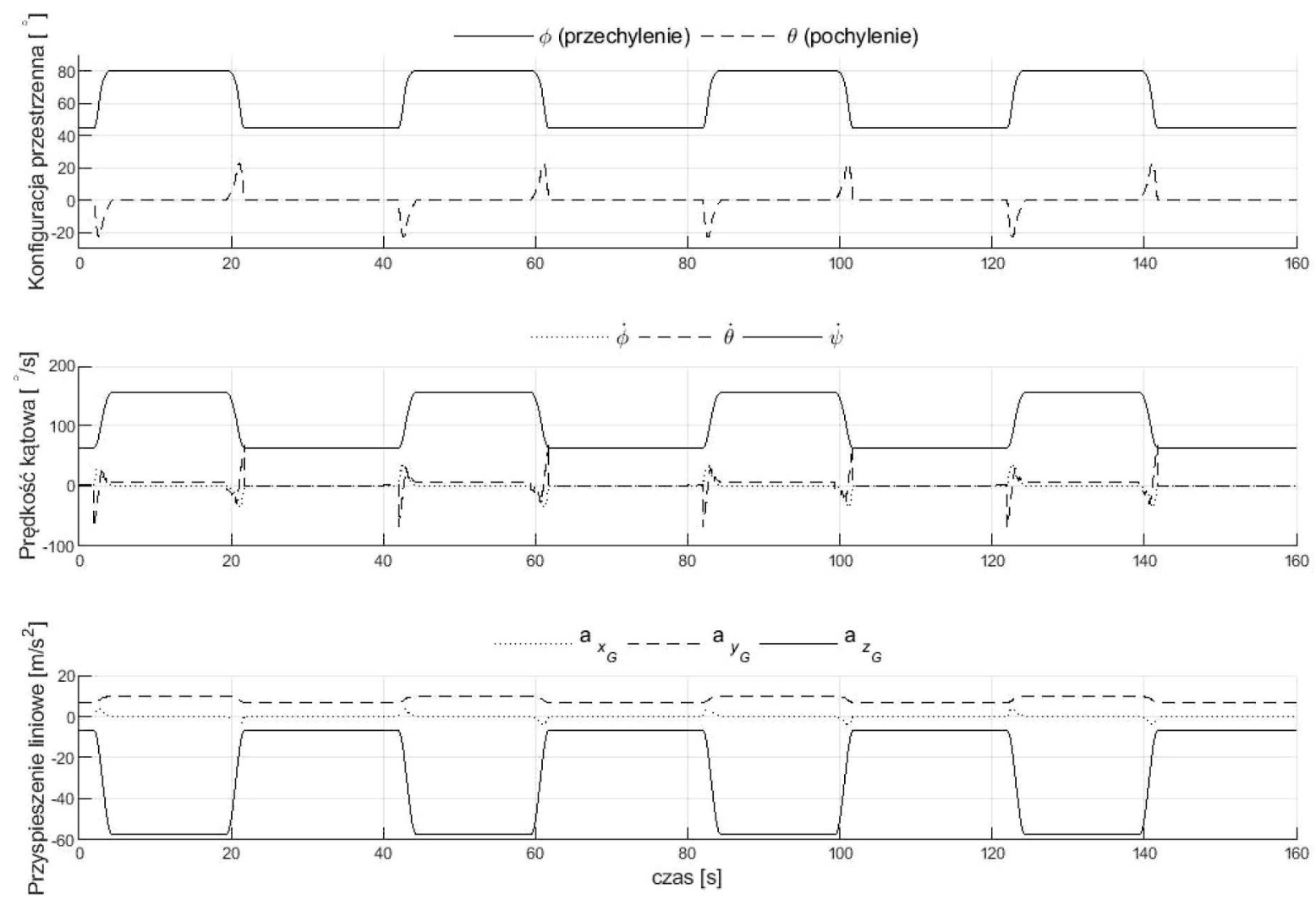

Rys. 2. Parametry kinematyki układu ruchu symulatora HTC-07 dla profilu przyspieszeń interwałowych $+6 \mathrm{G}_{\mathrm{z}}$ zmieniających się z szybkością $3 \mathrm{G} / \mathrm{s}$

\subsection{Prędkość kątowa oddziałująca na głowę pilota w symulatorze}

Podczas lotu w symulatorze na pilota znajdującego się w kabinie oddziałują zarówno przyspieszenie liniowe, jak i prędkości kątowe. O ile przedstawione na rys. 2 przyspieszenia opisane są w układzie współrzędnych związanym z głową pilota, tak widoczne prędkości kątowe opisują ruch poszczególnych członów układu ruchu symulatora (rys. 1) względem układu związanego z Ziemią. Przyjmując, że pilot podczas ekspozycji w symulatorze skierowany jest przodem do kierunku obrotu ramienia oraz nie wykonuje ruchów głową, wówczas osie układu związanego z głową pokrywają się z odpowiadającymi im osiami układu związanego z kabiną symulatora. Zachodzi zatem równość między prędkościami kątowymi kabiny i głowy $\left(\boldsymbol{\omega}_{G}=\boldsymbol{\omega}_{K}\right)$. Wyznaczenie składowych prędkości kątowej kabiny $\boldsymbol{\omega}_{K}$ sprowadza się do zsumowania prędkości kątowych ramienia $\dot{\psi}$, pierścienia $\dot{\phi}$ oraz kabiny $\dot{\theta}$ opisanych w układzie współrzędnych związanym z kabiną symulatora. Wyprowadzenie składowych prędkości kątowej $\boldsymbol{\omega}_{K}$ zostało szczegółowo opisane w pracy [22], a poniżej przedstawiono jedynie końcową postać równania

$$
\boldsymbol{\omega}_{K}=\left[\begin{array}{c}
p_{K} \\
q_{K} \\
r_{K}
\end{array}\right]=\left[\begin{array}{c}
\dot{\phi} \cos \theta-\dot{\psi} \cos \phi \sin \theta \\
\dot{\theta}+\dot{\psi} \sin \phi \\
\dot{\phi} \sin \theta+\dot{\psi} \cos \phi \cos \theta
\end{array}\right]
$$

w którym: $\dot{\phi}$ - prędkość przechylania, opisująca ruch obrotowy pierścienia, $\dot{\theta}$ - prędkość pochylania, opisująca ruch obrotowy kabiny/gondoli, $\dot{\psi}$ - prędkość odchylania, opisująca ruch obrotowy ramienia układu ruchu symulatora, $\phi$ - kąt przechylenia, który określa położenie układu związanego z ramieniem względem układu związanego z pierścieniem symulatora, $\theta$ - kąt pochylenia, który określa położenie układu związanego z pierścieniem względem układu związanego z kabiną. 
Powyższe kąty obrotów członów układu ruchu symulatora (ramienia, pierścienia i kabiny) przedstawiono na rys. 1.

Na rys. 3 przedstawiono obliczone za pomocą równania (2.1) składowe prędkości kątowej oddziałujące na pilota $\mathrm{w}$ kabinie symulatora podczas procedury osiągania i powrotu z poziomu $+6 \mathrm{G}_{\mathrm{z}}$.

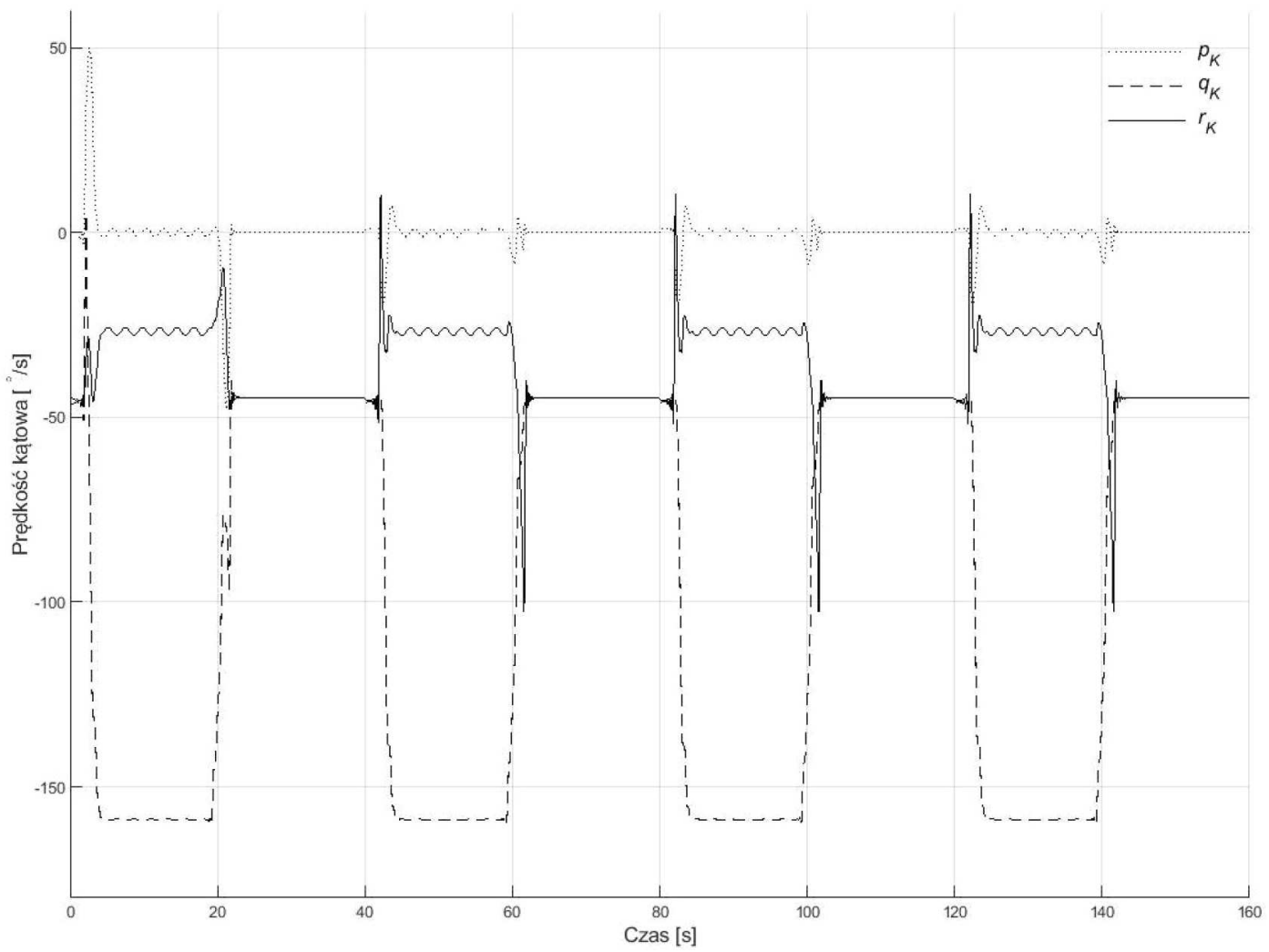

Rys. 3. Składowe prędkości kątowej oddziałujące na głowę pilota podczas odtwarzania w symulatorze HTC-07 profilu przyspieszeń interwałowych

Prędkość kątowa $\boldsymbol{\omega}_{G}$ (rys. 3) i przyspieszenie liniowe $\mathbf{a}_{G}$ (rys. 2) tworzą wektor bodźców ruchowych opisujący dane wejściowe modelu nasilenia objawów choroby lokomocyjnej (modelu MSI).

\section{Model nasilenia objawów choroby lokomocyjnej}

Spośród podjętych dotychczas prób opracowania modelu MSI [10] do oceny nasilenia choroby lokomocyjnej wybrano model opracowany przez Bosa i Blesa [23] i rozszerzony przez Kamiji i współpracowników [46]. Koncepcja tego modelu oparta jest na teorii konfliktu subiektywnego poczucia kierunku grawitacji (SVC) i w porównaniu do innych rozwiązań ma kilka istotnych zalet, m.in.:

- szacowanie ograniczone tylko do jednego konfliktu tj. SVC,

- w przeciwieństwie do modelu Omana [13] i Lawthera i Griffina [24], [25] brak wymogu specjalnego filtrowania sygnału wejściowego lub wyodrębnienia bodźca w postaci czystego ruchu pionowego,

- skuteczność w przewidywaniu objawów potwierdzona w licznych badaniach walidacyjnych z wykorzystaniem danych z badań eksperymentalnych [26]. 
Istotą teorii SVC jest założenie, że wszystkie sytuacje, które powodują chorobę lokomocyjną charakteryzują się stanem, w którym odczuwany kierunek grawitacji jest sprzeczny z subiektywnym poczuciem pionu, oczekiwanym na podstawie wcześniejszych doświadczeń [15]. Do wyjaśnienia objawów choroby lokomocyjnej wystarczające są bodźce ruchowe rejestrowane przez receptory narządu przedsionkowego (kanały półkoliste oraz narządy otolitowe) [27]. W związku z powyższym przy budowie modelu MSI założono, że pilot znajdujący się w kabinie symulatora nie odbiera z systemu zobrazowania scenerii lotu informacji o przestrzennym położeniu zarówno symulowanego statku powietrznego, jak i kabiny symulatora. Wyznaczenie subiektywnego poczucia kierunku grawitacji odbywa się zatem jedynie na podstawie integrowanych w ośrodkowym układzie nerwowym (OUN) sygnałów z receptorów narządu przedsionkowego.

Na rys. 4. przedstawiono opis budowy zastosowanego w obliczeniach modelu MSI. Wektor bodźców ruchowych opisujący przyspieszenie liniowe $\mathbf{a}_{G}$ oraz prędkość kątową $\boldsymbol{\omega}_{G}$, tworzy dane wejściowe modelu. Wektor ten opisany jest w układzie współrzędnych związanym z głową, w którym oś $x_{G}$ pokrywa się z osią nosowo-potyliczną i ma zwrot do przodu. Oś $y_{G}$ przechodzi przez kanały słuchowe lewego i prawego ucha i ma zwrot w prawo, zaś oś $z_{G}$ jest prostopadła do osi $x_{G}$ i $y_{G}$ i skierowana jest do dołu głowy.

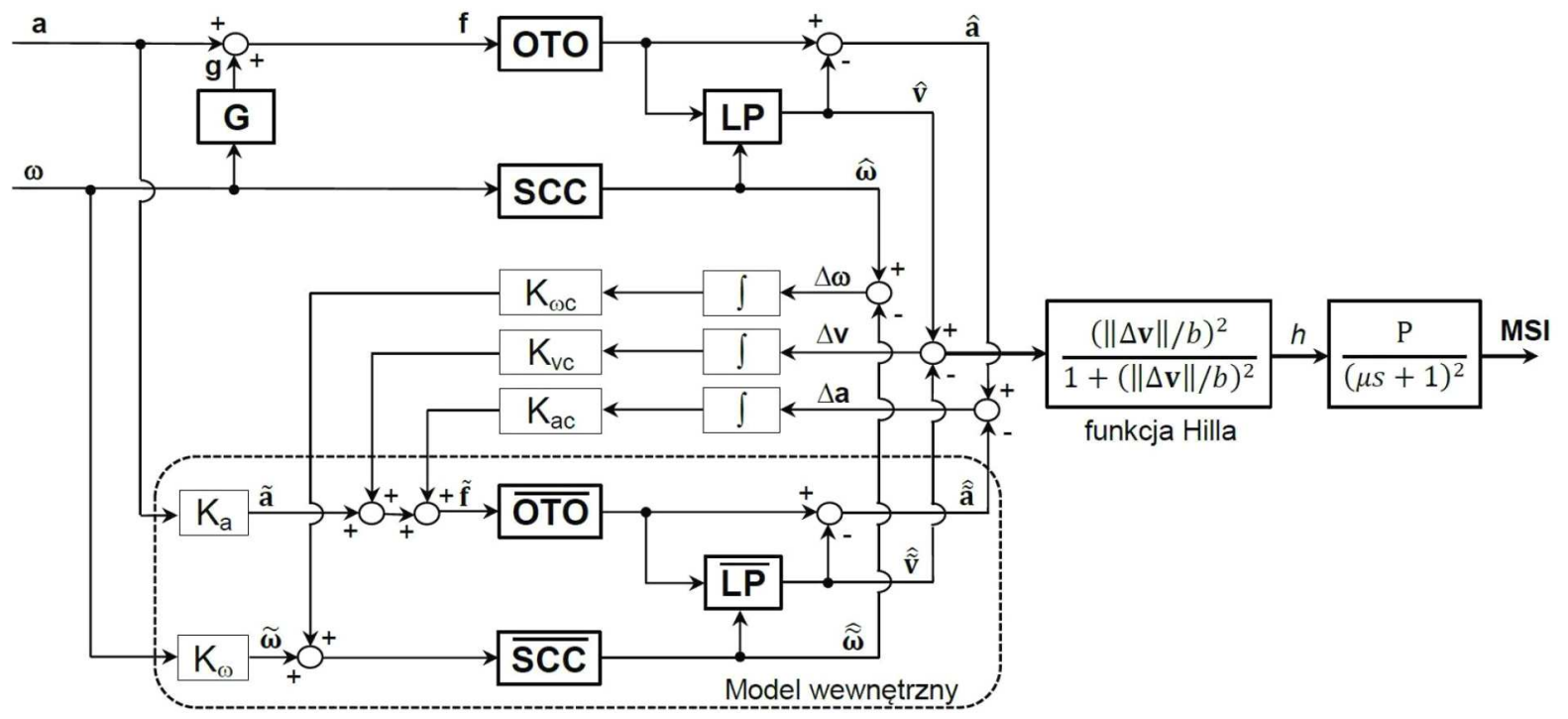

Rys. 4. Model choroby lokomocyjnej bazujący na teorii SVC

Składowe przyspieszenia grawitacyjnego g opisanego w układzie związanym z głową mogą być wyznaczone w oparciu o znany wektor prędkości kątowej $\boldsymbol{\omega}$. Składowe te zostały obliczone w następujący sposób (rys. 4, blok G)

$$
\frac{d \mathbf{g}_{G}}{d t}=-\boldsymbol{\omega}_{G} \times \mathbf{g}
$$

Bloki OTO oraz SCC reprezentują funkcje opisujące przetwarzanie fizycznych bodźców ruchowych odpowiednio na poziomie kanałów półkolistych oraz narządów otolitowych. Funkcja przejścia OTO jest określona przez macierz jednostkową, a jej sygnałem wejściowym jest wektor f który opisuje przyspieszenie wypadkowe, zwane także przyspieszeniem grawitacyjno-inercjalnym. Przyspieszenie to obliczane jest z zależności $\mathbf{f}_{G}=\mathbf{a}_{G}+\mathbf{g}_{G}$.

Sygnałem wejściowym kanałów półkolistych (blok SCC) jest wektor prędkości kątowej $\boldsymbol{\omega}_{G}$. Do obliczenia odczuwanej prędkości kątowej $\widehat{\omega}$ zastosowano transmitancję, która wyraża się wzorem [28]

$$
\widehat{\omega}_{i}=\frac{\tau_{2_{i}} \tau_{a} s^{2}}{\left(\tau_{2_{i}} s+1\right)\left(\tau_{a} s+1\right)} \omega_{G_{i}}
$$


gdzie: $\tau_{2}$ - długa stała czasowa, $\tau_{a}$ - stała czasowa adaptacji, $s$-operator Laplace'a, $i$ - oznacza oś $(i=x, y, z)$ układu współrzędnych związanego z głową.

Wykorzystując fakt, że przyspieszenie ziemskie jest stałe, a przyspieszenie bezwładności jest zwykle krótkotrwałe, odczuwany kierunek grawitacji $\widehat{\mathbf{v}}$ został wyodrębniony z przyspieszenia grawitacyjno-inercyjnego $\mathbf{f}_{G}[29]$. Przed wyznaczeniem wektora $\widehat{\mathbf{v}}$, odczuwalne przyspieszenie $\widehat{\mathbf{f}}$ jest przekształcane do układu współrzędnych związanego z Ziemią, w którym przyspieszenie grawitacyjne jest stałe. Wyodrębnione $\widehat{\mathbf{v}}$ podlega następnie odwrotnej transformacji do układu związanego z głową. Powyższe przekształcenia realizowane są w bloku LP (rys. 4) przy wykorzystaniu następującego równania [15]

$$
\frac{d \widehat{\mathbf{v}}}{d t}=\frac{1}{\tau}(\widehat{\mathbf{f}}-\widehat{\mathbf{v}})-\widehat{\boldsymbol{\omega}} \times \widehat{\mathbf{v}}
$$

gdzie: $\tau$ - stała czasowa, $\widehat{\mathbf{f}}$ - wektor odczuwalnego przyspieszenia grawitacyjno-inercyjnego (wektor ten reprezentuje odpowiedź narządu otolitowego na przyspieszenie grawitacyjnoinercyjne $\mathbf{f}_{G}$ ), $\widehat{\mathbf{v}}$ - wektor odczuwanego kierunku grawitacji, $\widehat{\boldsymbol{\omega}}$ - wektor odczuwanej prędkości kątowej, którego składowe oblicza się z zależności (2.2).

Model wewnętrzny układu przedsionkowego, który reprezentuje przetwarzanie na poziomie OUN został zakreślony ramką w dolnej części schematu blokowego (rys. 4). Bloki $K_{a}$ oraz $K_{\omega}$ to wzmocnienia, które reprezentują błędy oszacowania, odpowiednio przyspieszenia liniowego i prędkości kątowej. Występowanie tych wzmocnień można rozumieć jako wrażenia somatyczne, które obok sygnałów z narządu przedsionkowego pozwalają pilotowi człowiekowi na ocenę kinematyki ciała i dynamiki układu pilot-samolot.

Bloki $\overline{\mathrm{OTO}}$ oraz $\overline{\mathrm{SCC}}$ reprezentują odpowiednio model wewnętrzny narządu otolitowego i kanału półkolistego. Funkcja przejścia $\overline{\mathrm{OTO}}$ jest określona przez macierz jednostkową, natomiast funkcja przejścia $\overline{\mathrm{SCC}}$ jest opisana następującą transmitancją [30]

$$
\widehat{\widetilde{\omega}}_{i}=\frac{\tau_{2_{i}} s}{\tau_{2_{i}} s+1} \widehat{\omega}_{i}
$$

gdzie: $\tau_{2}$ - długa stała czasowa (jak w równaniu (2.2)), $s$ - operator Laplace'a, $i$ - oznacza oś $(i=x, y, z)$ układu współrzędnych związanego z głową.

Wektor oczekiwanego kierunku grawitacji $\widehat{\widetilde{\mathbf{v}}}$ wyznaczany jest w bloku $\overline{\mathrm{LP}}$ (rys. 4), za pomocą równania (2.3). Z różnicy wektorów $\widehat{\mathbf{v}} \mathrm{i} \underset{\widetilde{\mathbf{v}}}{\widetilde{ }}$ tworzony jest wektor konfliktu sensorycznego $\Delta \mathbf{v}$ (konfliktu między odczuwanym i oczekiwanym przez pilota kierunkiem grawitacji), który podobnie jak wektory $\Delta \mathbf{a}$ oraz $\Delta \boldsymbol{\omega}$ wykorzystany jest do aktualizacji wektora $\widehat{\widetilde{\mathbf{v}}}$. Wektory $\Delta \mathbf{a}$ i $\Delta \boldsymbol{\omega}$ oznaczają błędy między odczuwanymi $(\widehat{\mathbf{a}}, \widehat{\boldsymbol{\omega}})$, a oczekiwanymi $(\widehat{\widetilde{\mathbf{a}}}, \widehat{\widetilde{\boldsymbol{\omega}}})$ sygnałami, szacowanymi odpowiednio przez model układ przedsionkowego oraz model wewnętrzny (OUN). Błędy te po scałkowaniu i wzmocnieniu (bloki $K_{\omega c}, K_{v c}$ oraz $K_{a c}$ ) sac sumowane z sygnałami wejściowymi modeli wewnętrznych OTO oraz SCC.

W celu wyznaczenia wskaźnika MSI, wektor konfliktu sensorycznego $\Delta \mathbf{v}$ podlega nieliniowemu przekształceniu za pomocą funkcji Hilla [23] do postaci znormalizowanego parametru

$$
h=\frac{(|\Delta \mathbf{v}| / b)^{n}}{1+(|\Delta \mathbf{v}| / b)^{n}}
$$

gdzie: $\Delta \mathbf{v}$ - wektor konfliktu sensorycznego $(\Delta \mathbf{v}=\widehat{\mathbf{v}}-\widehat{\widetilde{\mathbf{v}}}), b$ - parametr, którego wartość dobierana jest $\mathrm{w}$ procedurze dopasowania modelu pod względem ilościowym do danych eksperymentalnych, $n$ - określa nachylenie funkcji $h, n \in[1, \infty)$.

Parametr $h$ jest następnie przekształcany za pomocą funkcji drugiego rzędu (rys. 4), której postać opisuje transmitancja [23]

$$
\mathrm{MSI}=\frac{P}{(\mu s+1)^{2}} h
$$


gdzie: $P$ - określa maksymalny procent osób, u których wystąpiły objawy choroby lokomocyjnej, $\mu$ - stała czasowa, $s$ - operator Laplace'a.

Szczegółowy opis przedstawionego powyżej modelu MSI został zamieszczony w pracach [10], [31]. Do budowy symulacyjnego modelu MSI oraz obliczeń wykorzystano oprogramowanie MATLAB (MathWorks, USA). Wszystkie parametry użyte w modelu przedstawiono w tabeli 1.

Tabela 1. Parametry modelu MSI

\begin{tabular}{|c|c|c|c|c|c|c|c|c|c|c|c|c|}
\hline$K_{a}$ & $K_{\omega}$ & $K_{\omega c}$ & $K_{v c}$ & $K_{a c}$ & $\begin{array}{c}\tau_{2_{x}} \\
{[\mathrm{~s}]}\end{array}$ & $\begin{array}{c}\tau_{2_{y}} \\
{[\mathrm{~s}]}\end{array}$ & $\begin{array}{c}\tau_{2_{z}} \\
{[\mathrm{~s}]}\end{array}$ & $\begin{array}{c}\tau_{a} \\
{[\mathrm{~s}]}\end{array}$ & $\begin{array}{c}\tau \\
{[\mathrm{s}]}\end{array}$ & $\begin{array}{c}b \\
{\left[\mathrm{~m} / \mathrm{s}^{2}\right]}\end{array}$ & $\begin{array}{c}\mu \\
{[\mathrm{min}]}\end{array}$ & $\begin{array}{c}P \\
{[\%]}\end{array}$ \\
\hline \hline 0,1 & 0,8 & 4,0 & 6,0 & 1,2 & 6,1 & 5,3 & 10,2 & 190 & 5 & 0,5 & 12 & 85 \\
\hline
\end{tabular}

\section{Wyniki obliczeń}

Analizowany w badaniu ruch kabiny wirówki przeciążeniowej (przyspieszenia liniowe - rys. 2 i prędkość kątowa - rys. 3) obejmował procedurę uzyskania przyspieszenia $+6 \mathrm{G}_{\mathrm{z}}$ oraz powrotu do poziomu przyspieszenia wyjściowego $+1,4 \mathrm{G}_{\mathrm{z}}$. Na rys. 5 przedstawiono wyniki badań numerycznych nasilenia objawów choroby lokomocyjnej (wskaźnik MSI), wyznaczone niezależnie dla pięciu profili różniących się prędkością zmiany przyspieszenia.

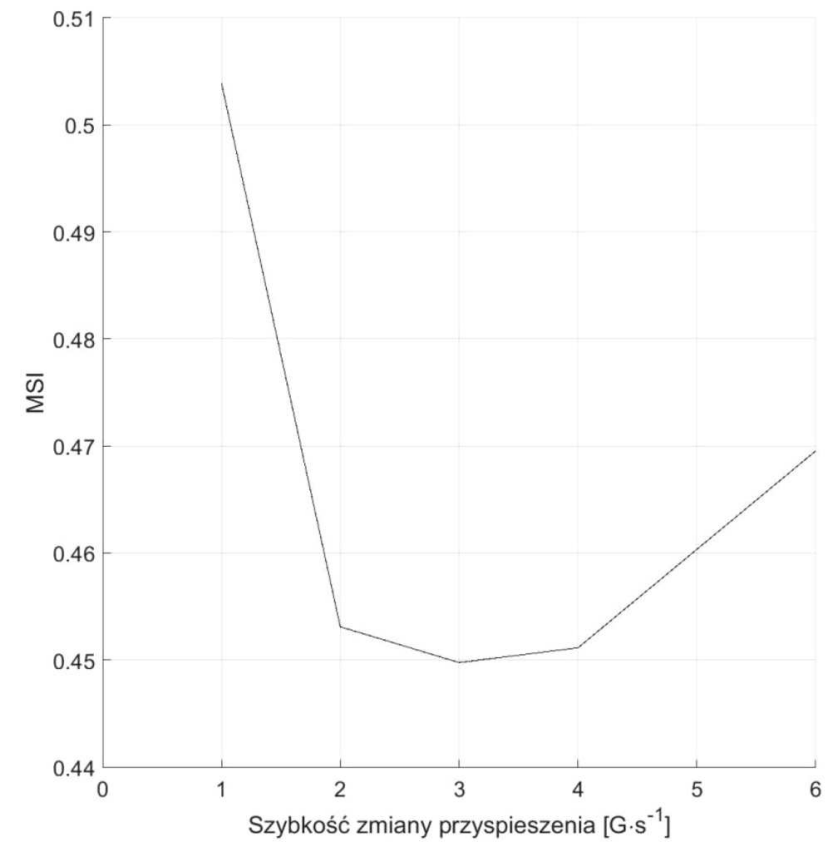

Rys. 5. Nasilenie objawów choroby lokomocyjnej (MSI) dla różnych szybkości zmiany przyspieszenia

Uzyskane wyniki MSI (rys. 5) wskazują, że dla każdego z analizowanych szybkości zmiany przyspieszenia kabiny wirówki występuje bodziec stymulujący do wystąpienia choroby lokomocyjnej. Widać, że wskaźnik MSI zmienia się w sposób nieliniowy. Najmniejsze nasilenie objawów choroby występuje przy szybkości zmiany przyspieszenia kabiny wirówki w przedziale od 2 do $4 \mathrm{G} / \mathrm{s}$, podczas gdy najwyższe dla szybkości $1 \mathrm{G} / \mathrm{s}$. Dla zmiany przyspieszenia z szybkością 5 oraz $6 \mathrm{G} / \mathrm{s}$ nasilenie tych objawów jest jedynie nieznacznie wyższe od wartości środkowych.

Rozpatrując zmiany poziomu przyspieszenia (z poziomu linii bazowej przeciążenia wyjściowego $1,4 \mathrm{G}_{\mathrm{z}}$ do przyspieszenia $+6 \mathrm{G}_{\mathrm{z}}$ ) jako oscylacje pionową (rys. 2), szybkości zmiany przyspieszenia z zakresu od 2 do $4 \mathrm{G} / \mathrm{s}$ odpowiadajac częstotliwościom od 0,28 do $0,56 \mathrm{~Hz}$. Wyniki badań [24], [26], [32], [33] wskazują, że oscylacja pionowa przy częstotliwościach od 0,1 do $0,5 \mathrm{~Hz}$ 
(z maksimum przy $0,16 \mathrm{~Hz}$ ) jest najbardziej sprzyjająca wywoływaniu objawów choroby lokomocyjnej. Może to zatem wyjaśniać znaczny wzrost wskaźnika MSI przy gradiencie $1 \mathrm{G} / \mathrm{s}$ (rys. 5), który odpowiada częstotliwości $0,14 \mathrm{~Hz}$. Zaskakujący jest jednak wzrost MSI dla szybkości zmian powyżej $4 \mathrm{G} / \mathrm{s}(0,56 \mathrm{~Hz})$, zważywszy na fakt, że oscylacje o wyższej częstotliwości (od 0,5 Hz) nie powodują uczucia dyskomfortu [33] lub innych objawów choroby lokomocyjnej [26]. Możliwym wytłumaczeniem tego wzrostu może być sprzężone krzyżowo przyspieszenie Coriolisa, które indukuje silny konflikt sensoryczny między receptorami narządu przedsionkowego (kanałami półkolistymi i narządem otolitowym) [27]. Przyspieszenie to pojawia się przy nagłej zmianie poziomu generowanego przyspieszenia, gdy zmieniają się prędkość obrotu ramienia symulatora i kąt przechylenia kabiny ( $\mathrm{w}$ tym głowy pilota). W takiej sytuacji narząd otolitowy oraz mechanoreceptory nie potwierdzają występującego ruchu obrotowego kabiny, który wykrywany jest jedynie przez kanały półkoliste narządu przedsionkowego. Rozbieżność tą można wyeliminować poprzez utrzymanie zmiany ruchu obrotowego poniżej progu ludzkiej percepcji [34]. Często do opisania progów czułości kanałów półkolistych narządu przedsionkowego używa się iloczynu przyspieszenia kątowego oraz czasu, w jakim ono działa. Iloczyn ten zwany stałą Muldera ma ustaloną wartość na poziomie $2^{\circ} / \mathrm{s}$ dla przyspieszeń kątowych o czasie trwania do 5 sekund [35].

Przedstawione na rys. 5 wyniki uzyskano przy założeniu, że pilot podczas wirowania nie wykonywał ruchów głową. W rzeczywistości podczas treningu pilot zwykle wykonuje ruchy, które dodatkowo pobudzają receptory narządu przedsionkowego. Wywołuje to u pilota silniejszy konflikt sensoryczny, przyczyniając się do wzrostu nieprzyjemnych doznań ruchowych prowokujących wystąpienie dolegliwości związanych z chorobę lokomocyjną [36]. Bles i współpracownicy [16] zaobserwowali, że jeśli podczas ekspozycji przy stałym przyspieszeniu osoby badane w wirówce przeciążeniowej pozostawały w bezruchu względem kabiny, to nie zgłaszały objawów tej choroby. Badania te ponadto wykazały, że najbardziej prowokującymi ruchami głowy są te ruchy, które wpływają na zmianę orientacji głowy względem odczuwanego kierunku grawitacji.

\subsection{Ograniczenia badania}

Istotnym ograniczeniem niniejszego badania jest niedoskonałość zastosowanego modelu nasilenia choroby lokomocyjnej (modelu MSI). Najważniejsze z tych ograniczeń to:

- brak danych empirycznych, które mogłyby posłużyć do walidacji modelu MSI w środowisku złożonego pola wysokich przyspieszeń. Model został poddany walidacji na bodźce ruchowe jedynie podobne, lecz nie takie same jak bodźce generowane przez wirówkę przeciążeniową. Ta niedoskonałość modelu nie dyskredytuje wyników, ale z pewnością ogranicza ich wiarygodność. W przyszłych badaniach należałoby przeprowadzić walidację modelu z wykorzystaniem danych z badań eksperymentalnych z udziałem pilotów,

- pominięcie w strukturze modelu zjawiska adaptacji [37]-[39], które polega na zmianie podatności na chorobę lokomocyjną jako funkcji wcześniejszych doświadczeń. Według Eliasa [40] możliwe jest wyeliminowanie tego ograniczenia poprzez zmniejszenie wzmocnienia [41], podniesienie progu wystąpienia [42] lub zmiany w dynamice rozwijania się objawów choroby lokomocyjnej [43].

\section{Wnioski}

Pomimo pewnych ograniczeń modelu MSI w zakresie użycia w środowisku przyspieszeń generowanych w wirówce przeciążeniowej, można przyjąć, że w analizowanych profilach występują bodźce ruchowe odpowiedzialne za występowanie choroby lokomocyjnej. Wyniki przeprowadzonych obliczeń numerycznych potwierdziły przypuszczenie, że podczas przejścia z poziomu przyspieszenia wyjściowego do wysokich przyspieszeń, nasilenie objawów choroby lokomocyjnej zależy od szybkości zmiany przyspieszenia liniowego. W oparciu o wyniki przeprowadzonej analizy sformułowano następujące wnioski: 
- w każdym z analizowanych przypadków szybkości zmian przyspieszeń kabiny wirówki występuje bodziec stymulujący wystąpienie objawów choroby lokomocyjnej,

- minimalne nasilenie objawów choroby lokomocyjnej występuje przy zmianie generowanego przyspieszenia w zakresie od 2 do $4 \mathrm{G} / \mathrm{s}$.

W związku z powyższym, rozwiązaniem najmniej korzystnym pod względem nasilenia objawów choroby lokomocyjnej jest profil, w którym zmiany przyspieszenia odbywają się z szybkością $1 \mathrm{G} / \mathrm{s}$ lub większą od $4 \mathrm{G} / \mathrm{s}$. Warto zaznaczyć, że wyniki te uzyskano dla przyspieszenia liniowego, które zmieniało się z ustaloną prędkością pomiędzy poziomami przyspieszenia wyjściowego $+1,4 \mathrm{G}_{\mathrm{z}}$ a przyspieszenia maksymalnego $+6 \mathrm{G}_{\mathrm{z}}$. Nie oznacza to zatem, że identyczne zależności wystąpią przy zmianie przyspieszenia pomiędzy innymi poziomami.

W celu potwierdzenia poprawności wyników obliczeń symulacyjnych, a zarazem skuteczności i poprawności modelu w przewidywaniu nasilenia objawów choroby lokomocyjnej, uzyskane w wyniki należałoby porównać z wynikami badań doświadczalnych przeprowadzonych z udziałem pilotów w rzeczywistej wirówce przeciążeniowej.

\section{Bibliografia}

1. Biernacki M.P., Dziuda Ł., Choroba symulatorowa jako realny problem badań na symulatorach, Medycyna Pracy, 63, 3, 377-388, 2012

2. Johnson D.M., 2005, Simulator Sickness Research Summary, RTO-TR-HFM-121-Part-II, 2005

3. Mccauley M.E., Research Issues in Simulator Sickness: Proceedings of a Workshop, 2nd ed., National Academies Press, Washington D.C., 1984

4. Cobb S.V.G., Nichols S., Ramsey A., Wilson J.R., Virtual reality-induced symptoms and effects (VRISE), Presence Teleoperators Virtual Environments, 8, 2, 169-186, 1999

5. Hettinger L.J., Berbaum K.S., Kennedy R.S., Dunlap W.P., Nolan M.D., Vection and simulator sickness, Military Psychology, 2, 3, 171-181, 1990

6. Temporary Flying Restrictions Due to Exogenous Factors Affecting Aircrew Efficiency, Medical Services, Headquarters Department of the Army, 2007

7. Kwarecki K., Zużewicz K., Symulatory ruchu i zarządzania bezpieczeństwem w transporcie, Bezpieczeństwo Pracy - Nauka i Praktyka, 2, 24-25, 2000

8. Kopyt A., NARkiewicz J., Technical factors influencing simulator sickness, Zeszyty Naukowe Politechniki Rzeszowskiej, 85, 22, 455-467, 2013

9. Biernacki M.P., Kennedy R.S., Dziuda Ł., Simulator sickness and its measurement with Simulator Sickness Questionnaire (SSQ), Medycyna Pracy, 67, 4, 545-555, 2016

10. Lewkowicz R., Modelling motion sickness, The Polish Journal of Aviation Medicine, Bioengineering and Psychology, 22, 3, 32-42, 2016

11. Reason J.T., Brand J.J., 1975, Motion Sickness, Academic Press, London, UK, 1975

12. Reason J.T., Motion sickness adaptation: a neural mismatch model, Journal of the Royal Society of Medicine, 71, 11, 819-829, 1978

13. OMAn C.M., A heuristic mathematical model for the dynamics of sensory conflict and motion sickness, Acta Oto-laryngologica. Supplementum, 392, 1-44, 1982

14. Oman C.M., Motion sickness: a synthesis and evaluation of the sensory conflict theory, Canadian Journal of Physiology and Pharmacology, 68, 2, 294-303, 1990

15. Bos J.E., Bles W., Modelling motion sickness and subjective vertical mismatch detailed for vertical motions, Brain Research Bulletin, 47, 5, 537-542, 1998 
16. Bles W., Bos J.E., De Graaf B., Groen E.L., Wertheim A.H., Motion sickness: Only one provocative conflict? Brain Research Bulletin, 47, 5, 481-487, 1998

17. AMST-Systemtechnik GmbH, 2011, User manual Human Training Centrifuge HTC-0\%, AmstSystemtechnik GmbH, Austria

18. Lewkowicz R., Kowaleczko G., 2018, Ocena jakości odwzorowania przyspieszeń w wirówce przeciążeniowej, [W:] Mechanika w Lotnictwie, ML-XVIII 2018, K. Sibilski (Red.), ZG PTMTS, Warszawa, 67-78, 2018

19. Burton R.R., Leverett S.D., Michaelson R.D., 1974, Man at High Sustained + Gz Acceleration, AGARD-AG-190, Neuilly-sur-Seine, France, 1974

20. Lewkowicz R., Kowaleczko G., An inverse kinematic model of the human training centrifuge motion simulator, Journal of Theoretical and Applied Mechanics, 57, 1, 99-113, 2019

21. Kvrgic V.M., Vidaković J., Lutovac M.M., Ferenc G.Z., Cvijanovic V.B., A control algorithm for a centrifuge motion simulator, Robotics and Computer-Integrated Manufacturing, 30, 4, 399-412, 2014

22. Lewkowicz R., Dochodzenie w sprawie wypadku lotniczego z zastosowaniem dynamicznego symulatora lotu, [W:] Mechanika w Lotnictwie ML-XIX, K. Sibilski (Red.), Instytut Techniczny Wojsk Lotniczych, Warszawa, 2020

23. Bos J.E., Bles W., Modelling motion sickness and subjective vertical mismatch detailed for vertical motions, Brain Research Bulletin, 47, 5, 1998

24. Lawther A., Griffin M.J., 1987, Prediction of the incidence of motion sickness from the magnitude, frequency, and duration of vertical oscillation, Journal of the Acoustical Society of America, 82, 3, 957-966, 1987

25. Lawther A., Motion Sickness Incidence on Sea-going Passenger Vessels, University of Southampton, Institute of Sound and Vibration Research, 1988

26. McCauley M.E., Royal J.W., Wylie C.D., O’Hanlon J.F., Mackie R.R., 1976, Motion sickness incidence: exploratory studies of habituation, pitch and roll, and the refinement of a mathematical model, Technical Report 1733-2, Human Factors Research Inc., California, Santa Barbara, 1976

27. Young L.R., Perception of the body in space: Mechanisms, [W:] Handbook of Physiology: The Nervous System III, Darian Smith I (Ed.), Oxford University Press lnc., 301-344, 1984

28. Haslwanter T., Jaeger R., Mayr S., Fetter M., Three-dimensional eye-movement responses to off-vertical axis rotations in humans, Experimental Brain Research, 134, 1, 96-106, 2000

29. Mayne R., A systems concept of the vestibular organs, [W:] Vestibular System Part 2: Psychophysics, Applied Aspects and General Interpretations, Springer Berlin Heidelberg, Berlin, 493-580, 1974

30. Glasauer S., Merfeld D.M., Modelling three dimensional vestibular responses during complex motion stimulation, [W:] Three-Dimensional Kinematics of Eye, Head and Limb Movement, M. Fetter, T. Haslwanter, H. Misslich (Ed.), Harwood Academic, 387-398, 1997

31. Kamiji N., Kurata Y., WadA T., Doi S., Modeling and validation of carsickness mechanism, [Proceedings of the SICE Annual Conference, Kagawa University, Japan, 1138-1143, 2007

32. O’Hanlon J.F., MCCauley M.E., Motion Sickness Incidence as a Function of the Frequency and Acceleration of Vertical Sinusoidal Motion, Goleta, California, 1973

33. Cheung B., Nakashima A., 2006, A Review on the Effects of Frequency of Oscillation on Motion Sickness, Toronto, Canada, 2006

34. Newman M.C., Minimizing Coriolis-Tumbling Intensity in a Centrifuge-Based-Flight Simulator, US9214092B2, 2015

35. Gillingham K.K., Previc F.H., Spatial Orientation in Flight, Report No. AL-TR-1993-0022, San Antonio, TX, 1993 
36. Tribukait A., Eiken O., Semicircular canal influence on the visually perceived eye level during gondola centrifugation, Aviation Space and Environmental Medicine, 77, 5, 500-508, 2006

37. Adenot S., Artificial Gravity: Changing the Intensity of Coriolis Cross-Coupled Stimulus with Head-Angle, Massachusetts Institute of Technology, 2004

38. Pouly J., Parametric Study of Vestibular Stimulation During Centrifugation, Massachusetts Institute of Technology, 2006

39. Elias P.Z., Jarchow T., Young L.R., 2008, Incremental adaptation to yaw head turns during 30 RPM centrifugation, Experimental Brain Research, 189, 3, 269-277, 2008

40. Elias P.Z., Jarchow T., Young L.R., Modeling sensory conflict and motion sickness in artificial gravity, Acta Astronautica, 62, 2-3, 224-231, 2007

41. Matsangas P., MCCauley M.E., 2005, A linear physiological visual-vestibular interaction model for the prediction of motion sickness incidence: Adaptation and Habituation Issues, [W:] Human Systems Integration Symposium, Arlington, Virginia, USA, 2005

42. Oman C.M., Influence of Adaptation on the Human Semicircular Canals and the Mole of Subjective Angular Velocity Cues in Spatial Orientation, MSc. Thesis., Massachusetts Institute of Technology, 1968

43. Young L.R., Oman C.M., Model for vestibular adaptation to horizontal rotation, Aerospace Medicine, 40, 10, 1076-1080, 1969

\section{Evaluation of motion stimuli responsible for the incidence of simulator sickness}

The presented work is an attempt to determine the cause of the occurrence of unpleasant motion sensations in a dynamic flight simulator, which are not encountered in a real flight. The aim of the research was to answer the question whether the rate of onset of the acceleration (G-onset rate) can be related to the occurrence of motion sickness symptoms in a pilot. To generate motion stimuli in the form of an interval acceleration profile, the human training centrifuge HTC-07 kinematics model was used. Each of the five generated profiles differed in the G-onset rate $(1,2,3,4$ or $6 \mathrm{G} / \mathrm{s})$. To assess the stimuli responsible for the occurrence of the simulator sickness, a motion sickness incidence model was used. The research conducted with the use of a computer simulation method showed that in each of the analysed acceleration profiles there was a motion stimulus responsible for the incidence of motion sickness. It was found that there was a non-linear relationship between the severity of sickness symptoms and the G-onset rate. The lowest level of symptom severity occurred for acceleration variations from 2 to $4 \mathrm{G} / \mathrm{s}$. 